\title{
Protection coordination in distribution systems with and without distributed energy resources- a review
}

\author{
Manohar Singh(1)
}

\begin{abstract}
Emission of greenhouse gases and depletion of fossil fuel reserves are two key drivers, which are forcing the mankind to generate the future energy demand from the renewable energy resources. These resources are generally distributed in nature and are directly integrated at distribution levels. Increasing penetration of the distributed energy resources in distribution power networks creates additional operational and control issues. These are mostly regulatory, economical load dispatching, power quality and protection issues.

Generally power distribution systems are protected with the help of dedicated over current based protection schemes. But increasing share of distributed energy resources penetration in electric utilities poses a serious threat to the existing protection coordination schemes of the distribution systems. Distributed energy resources connected distribution networks become interconnected in nature and protection coordination schemes, which are designed for unidirectional flow of fault currents become ineffective/non-functional.

Therefore, new protection coordination schemes are required for providing the adequate protection coordination for distributed energy resources connected electric power networks. In the available literature, the protection coordination schemes for radial distribution systems and developments in the area of protection coordination are discussed in detail. A thorough review for all these protection coordination schemes for distribution systems with and without distributed energy resources is done in this review article. It includes the analytical and artificial intelligence based techniques application for coordination of protective relays in the distribution systems. The limitations and research gaps in the area of protection coordination schemes are also presented in this review article.

The aim of this research paper is to bring all the available research in the area of relay coordination on one platform, so that it will help the emerging researcher to identify the future scope of relay coordination application for distributed energy resources connected distribution systems.
\end{abstract}

Keywords: Relay coordination, Distributed energy resources, Artificial intelligence, Adaptive relaying, And renewable energy resources

\section{Introduction}

Renewable energy resources (RES) are the promising sources of energy for future energy demand in most of the countries in the world [1]. These resources are site specific and their size varies from few kilowatts to megawatt depending upon the availability and location. Generally power generated from them is not bulk, as compare to thermal and nuclear power houses. Therefore, they do not require long power transmission corridors for power evacuation from generating units to the load centres. This

Correspondence: manoharsingh.cpri@nic.in

Central Power Research Institute, Bangalore, India results in less investment in long transmission circuits and requires low relatively cost local distribution circuits for supply of power in the local areas.

In a country like India, these are emerging as potential sources of supply of electric energy for rural electrification, where atleast 30 million people are yet un- electrified in the remote rural areas [2]. The scenario is mostly true for other developing countries as well as for under developed countries across the world. It is learned also that RES are emerging as major source of power in few European and other developed countries to cut the 
greenhouse gases emission from the conventional power plants [3].

The RES are distributed in nature and generally integrated in the distribution networks and are known as distributed energy resources $(D E R)$ [1]. Depending upon the size of $D E R$, their penetrations in the distribution system can be classified as either large scale penetration or small scale penetration. When they are of megawatt in size, they are generally integrated with the national grid. They may result in change of configurations of transmission/distribution networks due to their intermittent nature. Direct connections of DERs in the distribution systems have both merits and demerits from power economics, operation and control point of view. Operation, control and protection of distribution system become very complicated and challenging for the protection engineers, when DERs are directly connected with them [4].

Protection schemes are provided for distribution systems for quick disconnection of faulty section from the remaining healthy portion of power system. Main aim of protection schemes is to restrict the fault spread. Normally distribution lines and feeders are protected by over current relays [5]. Over current relays are used as primary as well as in backup protection relays for the distribution networks. However, their slow operating speed is not a desirable feature for their application as primary protection schemes for sub transmission systems. For sub transmission systems, distance relays are ideal choice for primary protection and over current relay are used in back up protection relays.

For an interconnected power networks, for each fault location on a line, relays are installed at near end bus and far end bus. The relay which is supposed to clear the fault first is known as primary relay. In over current relay coordination studies, failure of one over current relay is backed with other over current relays. The relays which are operating when the main relay fails to operate are known as backup relays [6]. The time-inverse curves of for an over current to over current relay coordination are shown in Fig. 1 for near end (F1) and far end (F2) faults.

For fault at F1 and F2, there should be sufficient coordination time margin (CTI1) between primary relay and backup relay time inverse relay characteristics. The operating time equation of a standard time inverse over current is given in (1) below.

$$
t_{o c}=\frac{\alpha^{*} T D S}{\left(\frac{I_{f}}{I_{p}}\right)^{\beta}-1}
$$

Where $t_{o c}$ operating time of over current relay, TDS is time dial setting, $I_{f}$ is fault current, $I_{p}$ is relay pickup current and $\alpha$ and $\beta$ are relay parameters as IEC standards [7].

Injections of $D E R$ jeopardize the existing protection coordination schemes for the distribution system. Impact depends upon number, size, type and location of $D E R$ in the distribution system. Moreover, as the location of $D E R$ in distribution system varies, the configuration of distribution systems also changes. Generally, the distribution systems are radial in nature and over current based protection schemes are set for unidirectional flow of fault currents. Penetration of DER usually causes meshed configuration of distribution systems and on majority of distribution feeders, fault current flows in both the directions [4]. The protection schemes which are designed for unidirectional flow of fault currents fails to provide the adequate protection coordination when $D E R$ power is injected in the distribution systems. Moreover, there is a

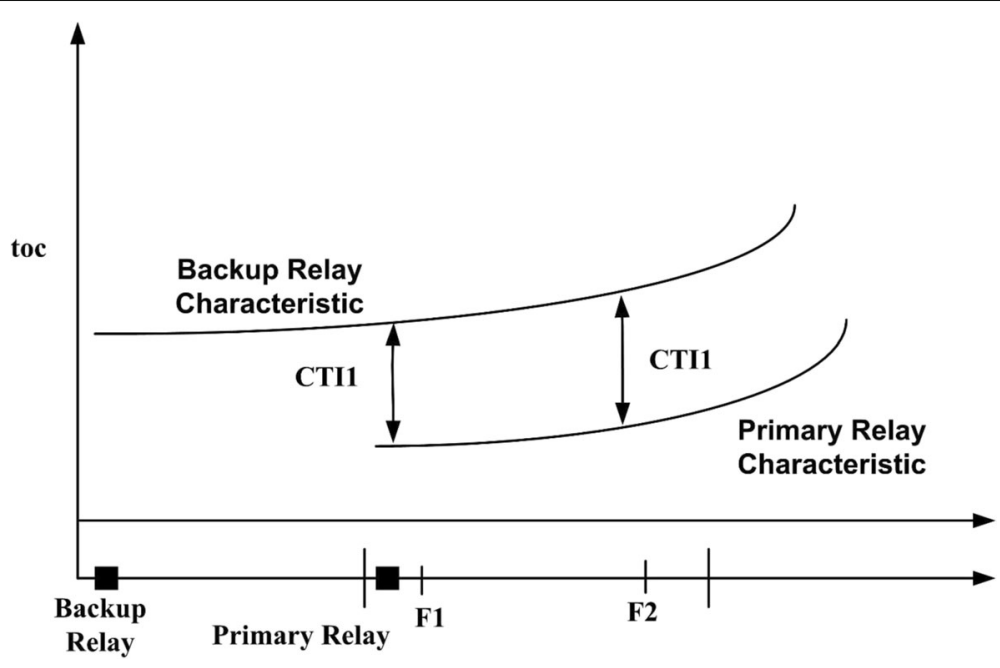

Fig. 1 Over current to over current relay coordination 
requirement of additional number of direction over current relays. The new settings of over current relays depend upon the location of new incoming $D E R$ in the distribution systems. In addition to these requirements, the impact may also reach to upstream transmission lines connected with downstream $D E R$ connected distribution systems. Under such operational conditions, the distance relays installed on the transmission line may result in underreact operation [8].

Generally, the distribution system operators are not willing to change the relay settings for each new incoming $D E R$ or any change in network topology. But from protection point of view, each relay requires new relay settings whenever the fault level changes in the network.

The small scale penetration is also known as microgrid operational mode [9]. These are small size of off grid $D E R$, generally feeding power to the local distribution networks. The main sources of power in such systems are photovoltaic based systems, which have limited fault feeding capabilities. The discrimination of fault current from load current is very complex in such distribution systems. Protection coordination and fault detection for a microgrid mode of operation is a complex protection job. In this review paper, new relay coordination techniques are discussed for protection of distribution system under larger scale and small scale penetration of $D E R$. The available literature in the field of protection coordination studies is presented in different sections in this article. At the end of this review paper, author has proposed various research gap and future scope of work for extending the research in the area of the power systems protection with renewable penetration.

\section{Protection coordination studies for radial distribution systems}

The different methods where developed for performing for protection coordination for transmission and distribution systems. These are classified based on the technique used in them, to solve the relay coordination problems. These can be broadly categorized as under.

\subsection{Curve-fitting techniques}

The time inverse-relay characteristics of over current relays are mathematically modelled using curve-fitting techniques. From these modelled time-inverse characteristics, time dial settings (TDS) and operating time of the over current relays are calculated. These methods began with a functional form such as polynomials function, which has the potential of approximating the published relay curves. Thereafter, the functional coefficients are determined by using computer, which best fits to the curves. Developmental work using these techniques up to 1989 are available in IEEE Committee report [10].
Curve-fitting techniques are simple techniques for setting of the relays, but they are inaccurate for currents setting less than 1.3 times pick-up current.

\subsection{Graph theory techniques}

Extensive research had been done on the application of graph theory for protection coordination studies [11-16]. Network structures are analysed by determining the break points for relay coordination studies [15]. In graph theory approach, the relay coordination starts from the certain set of relays known as break point relays (BPS). Proper selection of $B P S$ is very crucial for quick convergence of relay coordination problems. Graph theory was successfully applied for formulation of relative sequence matrix (RSM) [16, 17] and RSM later on used for determining the minimum break point relays as well as primary/backup $(B / P)$ relay pairs.

More systematic approaches based on the graph theory also are reported in $[18,19]$ to determine $B / P$ relays and RSM using only fundamental loop matrix and some other arbitrary matrices. In [20], a new graph theory based approach for calculating the loop matrix is reported. This technique is quite simple, fast and requires only half number of network the loops. Therefore, the need of generating all loops were eliminated in this technique [21] and only fundamental circuit matrix is sufficient to generate all the $\mathrm{B} / \mathrm{P}$ as well as $B P S$. A method based on the branches of the network was also reported in [22] for determining the minimum BPS. A heuristic based approach was also reported in the literature for finding the minimum BPS [23]. To reduce the complexity, another method has been presented in [24]. This method claims that, it gives the least number of break points and whole multi-loop network become a radial network.

Graph theory techniques are quite useful for solving the relay coordination for interconnected distribution systems, but computation times for solving the over current relay coordination problem is being exponential function of network dimensions and a lot of unutilised intermediate data is generated.

\subsection{Analytic methods}

In $[25,26]$, analytical based methods for identification of critical fault points for solving the relay coordination problem were discussed. An approach based on the "interior point primal-dual algorithm" was discussed in [27] where additional constraints were imposed by distance relays and breaker failure on relay coordination studies. Gradient search based technique was also applied successfully for optimization of relay coordination problems for mid line faults [28]. These techniques generally take large number iteration to compute the relay settings and fails to 
give the optimal relay setting for interconnected power network. However analytic methods are very effective for radial systems.

\subsection{Optimization techniques}

The relay coordination problems solution using analytic methods was very time consuming for complex and big size power systems. However, proper selection of BPS relay helped in reducing the convergence time of the relay coordination problem. Application of optimization algorithms for solving the relay coordination problems had eliminated the need of BPS relays. However, graph theory is still used for formulation of the RSM for identification of $\mathrm{B} / \mathrm{P}$ relay pairs. The optimization methods used for relay coordination can be broadly classified in two groups as under.

\subsubsection{Mathematical based optimization methods}

Application of mathematical based optimization methods for relay coordination was first time proposed by A.T. Urdanta et al. in 1988 [6]. In that paper, two techniques were suggested for solving the time inverse over current relay coordination problem. First technique was applicable for fixed network configuration and second one was for a variable network configuration. The optimization problems were formulated as a minimax problem for multiple network configurations. In [29] a methodology based on the linear programming and considering the definite time backup relays for optimal relay settings was presented. Linear programming methods were simple and easily converge to optimal solutions. But they were only helpful for optimal selection of TDS of over current relays. Designer experience was used for selection of plug settings (PSs) of over current relays in relay coordination problems.

Application of simplex, dual simplex, two phase simplex and big- $\mathrm{M}$ (penalty) methods for relay coordination were also reported in [30]. Another technique was proposed in [31], in which linear programming was used to optimize the TDSs and PSs was optimized using nonlinear programming. Linear programming approach based on interval analysis concept was also used for solving the directional over current relays (DOCRs) coordination problems. These techniques also considers the effect of network uncertainty in defining the relay coordination problem [32, 33]. In [34-36], linear programming methods were discussed in which constraints relaxation was also considered for optimal coordination of over current relays for interconnected power networks.

Non-linear based optimization $(N L P)$ techniques were also applied successfully for optimal selection of TDSs and PSs in the relay coordination problems. Nonlinear optimization based on General Algebraic modelling $(G A M S)$ and sequential quadratic programming (SQP) [37] are reported in the literature. Application of random search technique (RST) for solving the relay coordination problems are also discussed in [38]. In [39], an advanced relay coordination method for over current relays using nonstandard tripping characteristics was applied successfully for solving the relay coordination problems.

\subsubsection{Artificial intelligence based optimization techniques}

Optimization techniques based on artificial intelligence are reported in literature. These techniques are used for solving/obtaining the global optimal settings of relays for interconnected power networks. Application of genetic algorithm $(G A)$ for relay coordination has been reported in [40]. For interconnected power networks, large number of selectivity constraints, may cause the infeasible solution of relay coordination problems. For such relay protection coordination problems, pre-processing of the selectivity constraints is done to remove the least efficient selectivity constraints from the efficient selectivity constraints [41]. The least effective selectivity constraints are identified with the help of area called possible solution area $(P S A)$ for each relay pair, i.e. primary and backup relays. Continuous genetic algorithm (CGA) technique applied for optimum coordination of DOCR in a ring fed distribution system [42].

A hybrid GA-NLP based approach is also implemented for determination of optimum values of TDSs and PS of DOCRs [43]. Evolutionary programming is a stochastic multi-point searching optimization algorithm and is capable to escape from local optimum solutions. A hybrid GA based method, was introduced to solve the relay coordination problem for different network topologies [44]. Hybrid GA based solution is also used to improve the convergence of the of relay optimization problems [45]. In the relay coordination studies, it is learned that there is no upper limit of the CTI and fitness function is optimised without putting any upper limit of CTI [46]. This is one of the limitations seen in the existing relay coordination studies and a solution is proposed by the author in [47]. Additional selectivity constraints are created to put an upper limit on the CTI. Another method using $G A$ applied for over current relays coordination, considering the priority for constraints is applied for solving the optimal setting of DOCRs.

Particle swarm optimization (PSO) algorithm was proposed to calculate discrete values for the PSs [48]. A modified form of PSO for the optimal coordination of DOCRs was also reported in [49]. Laplace Crossover particle swarm optimization (LXPSO) had been applied successfully for optimal setting of over current relays [50-52]. Modified differential evolution $(D E)$ algorithm based techniques are also reported in [53-55] for optimal setting of DOCRs. In [56], non-heuristic method, for solving relay 
coordination problem without formulation of objective function was presented. While in [57], an efficient hybrid algorithm based on Shuffled Frog Leaping (SFL) algorithm and $L P$ was applied for solving relay coordination problems. In that paper, a hybrid approach based SFL and $L P$ was used as global and local optimizers respectively. Seeker algorithm which is based on the act of human searching was also reported in [58] for relay coordination applications. In $[59,60]$, artificial bee's colony $(A B C)$ and ant colony algorithms were traced for solving the relay coordination problems. It was claimed that these algorithm leads better convergence of relay coordination problems as compare to PSO. In [61] biogeography-based optimization $(B B O)$ algorithm was applied for solving the relay coordination problem.

Mathematical based optimization methods are suitable for radial power networks. For meshed power networks, the number of relays and accordingly the combination of relay coordination pairs are quite large. This results in creation of large dimensional constrains matrix. Since the relay coordination problems are non-convexity in fitness function and constrains. Since mathematical based optimization programming has tendency of trapping in local minima for non-convex problems. This limitation had led the researchers to explore the application of artificial intelligence based optimization algorithms for obtaining the global minima solution for relay coordination problems. The global optimal solution/setting are obtained after properly tuning the optimization parameters of artificial intelligence based algorithm.

\subsection{Fuzzy and neural network based methods}

Applications of few fuzzy and neutral network based methods were also traced in the literature. These methods were used for modelling the over current relays operating curves [62]. The feed forward multi-layer perceptron neural networks were used for calculation of the operating times of over current relays for various TDS. In [63], an automated fault location method was discussed which was developed using a two stage radial basis function neural network (RBFNN). In this method, first RBFNN determines the fault distance from each fault source and second RBFNN identifies the exact faulty line. Multi-layer perceptron $(M L P S)$ neural networks were also used for determination of faults in the distribution networks. Applications of neural network for protection of distribution networks in $D E R$ connected scenario were also discussed in the [64].

\subsection{Adaptive relaying based methods}

Relays are set for a predefined network configurations. Protection engineers select the settings of relays settings after analysing all the critical power system conditions.
In reality, it is not only difficult to identify and analyse all critical operating conditions of power system in advance. But it is also difficult to determine relay settings that will be optimum for all power network operating conditions. However, with the development of microprocessor based relays, now scenario has been changed. Micro-processor relay can store, collect information, handle complex logic and communicate with other relays and control devices. This feature of micro-processor based relays had made it possible to continuously monitor the state of a power system, analyse it in real-time and change the relay settings to as per the prevailing network conditions. In $[65,66]$, an adaptive relaying concepts for protection of transmission lines were discussed in details. In [66, 67] software based adaptive relaying implementations for transmission line protection were discussed. Figure 2, shows the various functional elements of adaptive relaying.

Continuous monitoring of network topology and line loading are sensed in this protection scheme. The required settings of over current relays are updated in online manner as per variation in fault current levels seen by relays during changing network conditions. In [68], design, implementation and few remedial measures for adaptive relaying failures were demonstrated using a relay hardware model implementation for a power system in Research Laboratory of University of Saskatchewan. In this designed scheme, the adaptive relaying scheme responds reliably to change in load currents, expected fault currents change and system topology changes. Adaptive relaying scheme takes into consideration that status of a power system changes in reality and thus the settings of relays need to be changed in on-line mode to accommodate these network changes.

An on-line relay coordination algorithm based on linear programming technique was reported in [69]. In $[69,70]$, adaptive optimal methodology based on a modified PSO technique were applied for selection of over current relay settings during on line mode according as per the prevailing network topology. The pre-solution and filtering simplification techniques were used prior to the application of linear programming algorithm for reducing the size and complexity of system [27]. The interior point based approach reaches close to the vicinity of the final optimal result hardly in only one or two iteration. Therefore this protection scheme is very suitable for the online application in adaptive relaying protection.

The adaptive protection coordination approaches have promising future application for DER connected distribution systems. In these networks, the fault levels are intermittent and continuously changing as per connection of DER in the network. The generalised summary of different techniques used for protection coordination of distribution systems are listed in Table 1. 


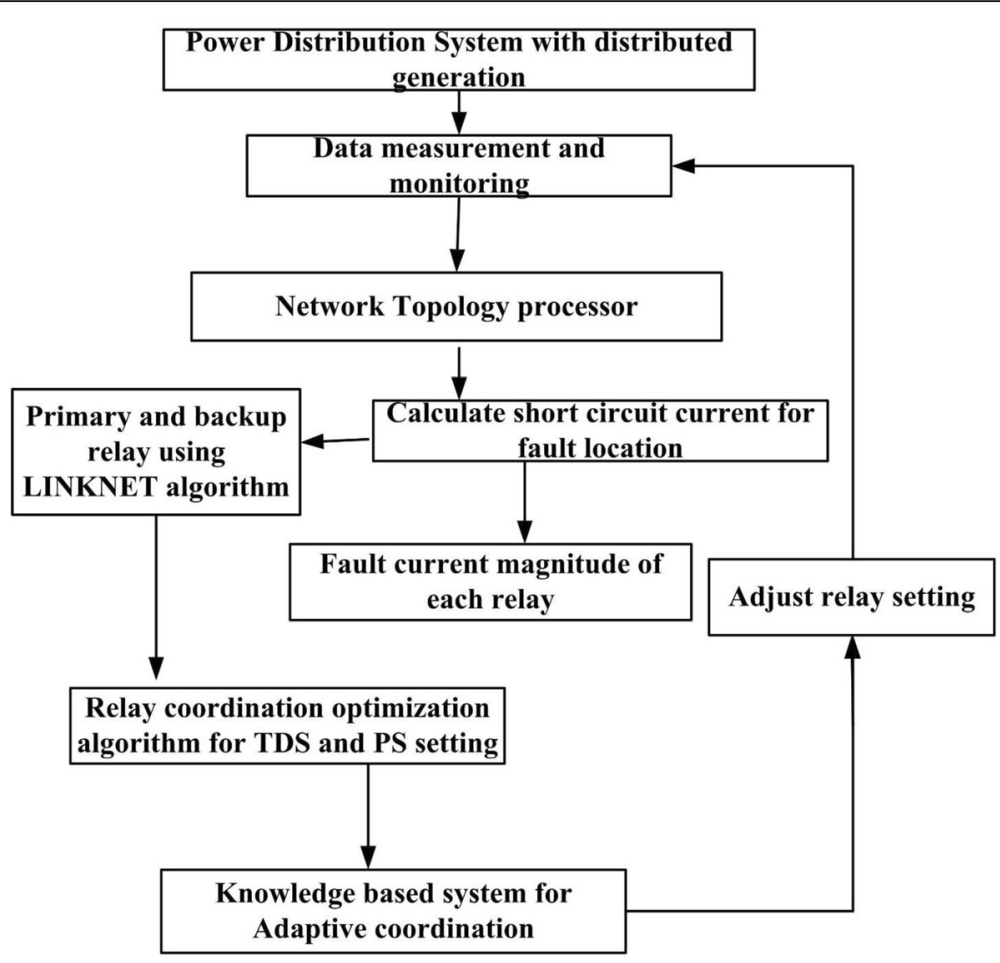

Fig. 2 Adaptive relaying scheme

Table 1 Summary of different techniques used for protection coordination of distribution systems without DER penetration

\begin{tabular}{|c|c|c|c|}
\hline Technique & Main feature & Merits & Demerits \\
\hline Curve fitting [1] & $\begin{array}{l}\text { Time inverse operating characteristics } \\
\text { are generated for various types of linear } \\
\& \text { non-liner functions relay time } \\
\text { operating curves. }\end{array}$ & Only method was available at that time. & Poor accuracy \\
\hline Graph theory $[3,5,7]$ & Break point relays are identified & $\begin{array}{l}\text { Proper selection of break point lead to } \\
\text { converged solution of relay coordination } \\
\text { problems. }\end{array}$ & Selection of break point is critical \\
\hline Analytical method [16-19] & $\begin{array}{l}\text { Gradient, lagrange multiplier and other } \\
\text { classical problem formulation are } \\
\text { formulating relay coordination } \\
\text { problems. }\end{array}$ & $\begin{array}{l}\text { Mostly applicable for radial distribution } \\
\text { systems. }\end{array}$ & $\begin{array}{l}\text { Requires large no. of iteration and } \\
\text { initial guess is essential for } \\
\text { convergence of the solution of } \\
\text { problem. }\end{array}$ \\
\hline $\begin{array}{l}\text { Linear optimization } \\
\text { Based Techniques }[22,23]\end{array}$ & $\begin{array}{l}\text { Relay coordination problem is } \\
\text { formulated as linear programming } \\
\text { problem. }\end{array}$ & Helpful for optimizing only TDS & $\begin{array}{l}\text { PS are selected based on the } \\
\text { experience of the designer/ } \\
\text { operator }\end{array}$ \\
\hline $\begin{array}{l}\text { Non-Linear optimization } \\
\text { Based Techniques [30] }\end{array}$ & $\begin{array}{l}\text { Relay coordination problem is } \\
\text { formulated as non-linear programming } \\
\text { problem }\end{array}$ & Both TDS and PS are selected optimally. & $\begin{array}{l}\text { Since relay coordination problem } \\
\text { are non-convex, therefore there is } \\
\text { chance of local minima trap. }\end{array}$ \\
\hline $\begin{array}{l}\text { Hybrid optimization } \\
\text { techniques }[38,40] .\end{array}$ & $\begin{array}{l}\text { Both analytic and optimization method } \\
\text { are applied. }\end{array}$ & $\begin{array}{l}\text { Capable to solve the relay coordination } \\
\text { problem for big interconnected systems } \\
\text { and global optimal solution can be easily } \\
\text { achieved. }\end{array}$ & Works for fixed network topology. \\
\hline $\begin{array}{l}\text { Fuzzy \& neuro based } \\
\text { optimization [55] }\end{array}$ & $\begin{array}{l}\text { Concept of fuzzy and training of } \\
\text { neurons is extended for protection } \\
\text { coordination problems. }\end{array}$ & $\begin{array}{l}\text { Effective protection coordination for } \\
\text { different network pre-identified network } \\
\text { topologies. }\end{array}$ & $\begin{array}{l}\text { Fails for respond when new } \\
\text { network topology comes in } \\
\text { existence during operational } \\
\text { conditions. }\end{array}$ \\
\hline
\end{tabular}




\section{Protection coordination schemes for sub-transmission systems}

Sluggish operating speed of over current relays does not favour their application in main protection for subtransmission power networks [71]. In such power networks, the distance relays are used as main protection relays and over current relays are used as backup protection relays. The time inverse over current relay characteristics and different zones settings of distance relays are shown in the Fig. 3.

Critical points $F 2, F 4$ and $F 5$ correspond at which the selectivity margins (CTI2 and CTI3) between distance relays and over current relays are at minimum. The literature reported research work done for combine distance and over current relay coordination is discussed as under.

In [72], an algorithm for distance and over current relays coordination is discussed which uses $G A$ as solver. In this article, the fitness function for optimal combine distance relays to over current relays coordination is formulated by adding new terms to the time inverse over current relay coordination fitness function as discussed in [6]. Additional terms in fitness function of time inverse over current relay coordination problem, results in optimal selection of zone- 2 for distance relays. The various time-inverse over current relay characteristics are considered for each back up over current relay and the best of them are selected using $G A$ as a solver. In [73], another method was also discussed for optimization of zone-2 operational time of distance relays. This method provides better backup protection and higher line protection coverage as compare to other methods.

Another method for automatically determining the optimum timing for Zone-2 of distance relays with directional over current relays had been discussed in [74]. In [74], optimal coordination between distance relays and directional over current relays for a series compensated lines had been discussed. In order to solve this non-linear and non-convex combine distance and over current relay coordination problem, a modified adaptive particle swarm optimization (MAPSO) was used in [75].

The downstream penetration of $D E R$ from distribution systems may affect the coordination between distance and over current relays at sub-transmission level. The above discussed techniques mainly considers the fixed zone- 2 operating time of distance relays and standard time-inverse characteristics for backup over current relays. These fixed type of relay characterises for distance and over current relays may fail to maintain the proper coordination between distance and over current relays during downstream in-feed from DER at distribution systems. The brief review of main points of other protection coordination for sub-transmission systems are given in Table 2.

\section{Protection coordination for distribution systems with DER}

One of major problem associated with $D E R$ connected distribution systems is the design of proper protection coordination schemes. It has been observed that, classical protection schemes of radial distribution system will not work reliably for $D E R$ connected distribution systems. Therefore, new protection schemes are required for protection of $D E R$ connected distribution systems, which will provide reliable protection during grid connected and islanding mode of network operation.

The protection coordination problem in $D E R$ connected distribution systems may be classified as large scale and

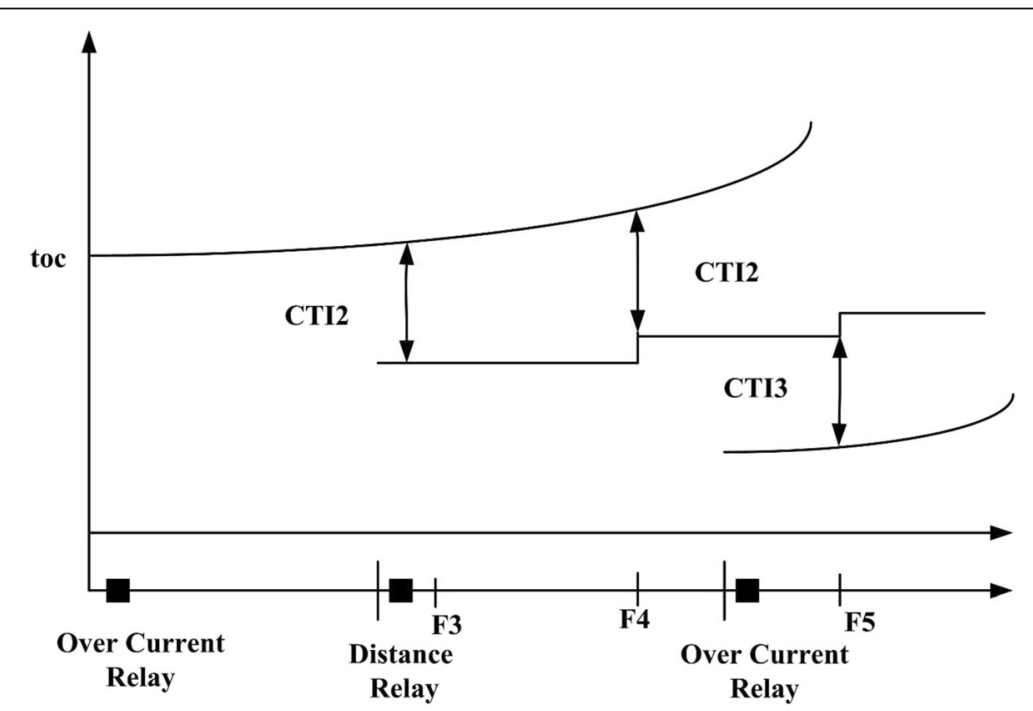

Fig. 3 Distance to over current relay coordination 
Table 2 Summary of different techniques used for protection coordination of sub-transmission systems

\begin{tabular}{|c|c|c|c|}
\hline Technique & Main feature & Merits & Demerits \\
\hline $\begin{array}{l}\text { Intelligent distance to over current } \\
\text { relay coordination }[62,64]\end{array}$ & $\begin{array}{l}\text { Performs the coordination operation } \\
\text { of distance and over current relays }\end{array}$ & $\begin{array}{l}\text { Utilizes the different standard } \\
\text { time inverse over current relay } \\
\text { and optimized zone-2setting } \\
\text { of distance relays for coordination. }\end{array}$ & $\begin{array}{l}\text { No hardware implementation } \\
\text { reported. }\end{array}$ \\
\hline $\begin{array}{l}\text { Definite time based distance to over } \\
\text { current coordination [66] }\end{array}$ & $\begin{array}{l}\text { Definite time based over current relays } \\
\text { are coordinated with distance }\end{array}$ & Simple in implement & $\begin{array}{l}\text { Over current relays have } \\
\text { fixed operating time. }\end{array}$ \\
\hline $\begin{array}{l}\text { Optimized coordination for series } \\
\text { compensation line [67] }\end{array}$ & $\begin{array}{l}\text { Multiple relay settings are identified for } \\
\text { different level of series compensation }\end{array}$ & $\begin{array}{l}\text { Applicable for varying degree of } \\
\text { series compensation. }\end{array}$ & $\begin{array}{l}\text { Real-time implementation } \\
\text { challenges }\end{array}$ \\
\hline
\end{tabular}

small scale penetration protection impacts. The large scale impact is distributed and may spread to upstream transmission network. The impact may be observable in term of change in short circuit currents in upstream transmission networks. This will require new relay settings for protection of distribution system as well as sub-transmission systems. This requirement also may arise when the network topology changes due to incoming of new DERs. Proper combination of primary/backup relays pairs are identified for each new incomer $D E R$ in the distribution system. Moreover, additional numbers of directional over current relays are required for new DERs in the distribution systems and they will results in new combination of primary/backup over current relay pairs. Identification of correct combination of primary/backup relay pairs is a tedious task for interconnected distribution networks. A network topology processor algorithm is utilized for identification of correct combination of primary/ backup relay pairs under different location of DERs in the distribution networks.

The new protection schemes must be equipped efficient data monitoring, communication and intelligence and are known as wide area measurement protection and control. In the literature, few such type of protection schemes are discussed which uses multi-agent system (MAS) and artificial intelligence $(A I)$ based technology with distributed control for protection of such power networks. These techniques are superior to the local protection schemes in terms of distributed control, speed, reliability and are also equipped have artificial intelligence feature. These types of protection coordination schemes has potential application for protection of future distribution system where the share of $D E R$ will be quite high as compare to present status of DER penetration [76]. Presently in India, injection of $D E R$ is around $12 \%$ of total power demand. In some western countries this injection level is higher as compare of Indian scenario. Although with present $D E R$ penetration level in India, the protection coordination is not much effected. But by 2020, India is expecting around $100 \mathrm{GW}$ (25\% of total demand) DER injection in the distribution networks [77]. This future bulk injection of DER may cause more challenges for the protection of distribution systems with existing protection coordination methods.

The effects of $D E R$ on existing relay coordination in mainly depend on size, type, and placement of DERs in the distribution systems. Apart from these factors, the impact also depends on the characteristics of the distribution network and type of connected DER. Shortcircuit faults currents from a wind farms mainly depends on wind turbine generator type and network configuration [78]. On the other hand, synchronous generators are able to feed large sustained fault current irrespective to the network configurations. While in case of inverter based DER systems, short circuit currents are very low equivalent to their rated current. Recently few researchers had published few articles on impact on relay coordination for DER connected distribution. Brief summary of these papers is discussed in this review paper as under.

\subsection{General protection schemes}

A. Girgis et al. [4] discussed about the effect of high penetration of $D E R$ on coordination of protective device and suggested an adaptive protection scheme as a solution for maintain the protection coordination in $D E R$ connected distribution systems. When DER connected, a part of the distribution system may lose its radial nature and subsequently coordination among the protective relays may be lost. As a general practice in utilities, DERs are disconnected from the distribution system during faults and distribution system becomes radial in nature. However this results in losing the support of DER during the fault conditions. To solve the problem of disconnecting all downstream DERs during faults, a systemindependent adaptive protection scheme was discussed in [79] to achieve the stable fuse-relay coordination. Other techniques are also discussed in [80-82], in which the impact of $D E R$ on classical protection is first analysed. In these papers, a novel adaptive non-pilot over current protection scheme is presented, which utilizes the steady state fault currents for maintain the sable protection coordination. In [83], a non-adaptive relaying scheme is discussed, which utilised the fault current limiter $(F C L)$ to locally limit the $D E R$ fault current during fault conditions and 
thus restores the original coordination among the relays. In [84], the over current relay coordination in DER connected distribution systems are maintained by adaptive and non-adaptive relaying schemes.

In adaptive relaying scheme, the settings of the over current relay are re-defined which are mal-operating due to $D E R$ fault current contribution in the distribution system. In case of non-adaptive relaying scheme, FCLs are placed in series with $D E R s$ to block the fault current during the fault conditions [84]. Figure 4 shows the algorithm, which is used to select the optimal size of $F C L$ in distribution system to maintain the relay coordination in DERs connected distribution systems.

In [85], a method based on online estimation of the equivalent circuit parameters and application of the equivalent circuit to estimate the required short-circuit

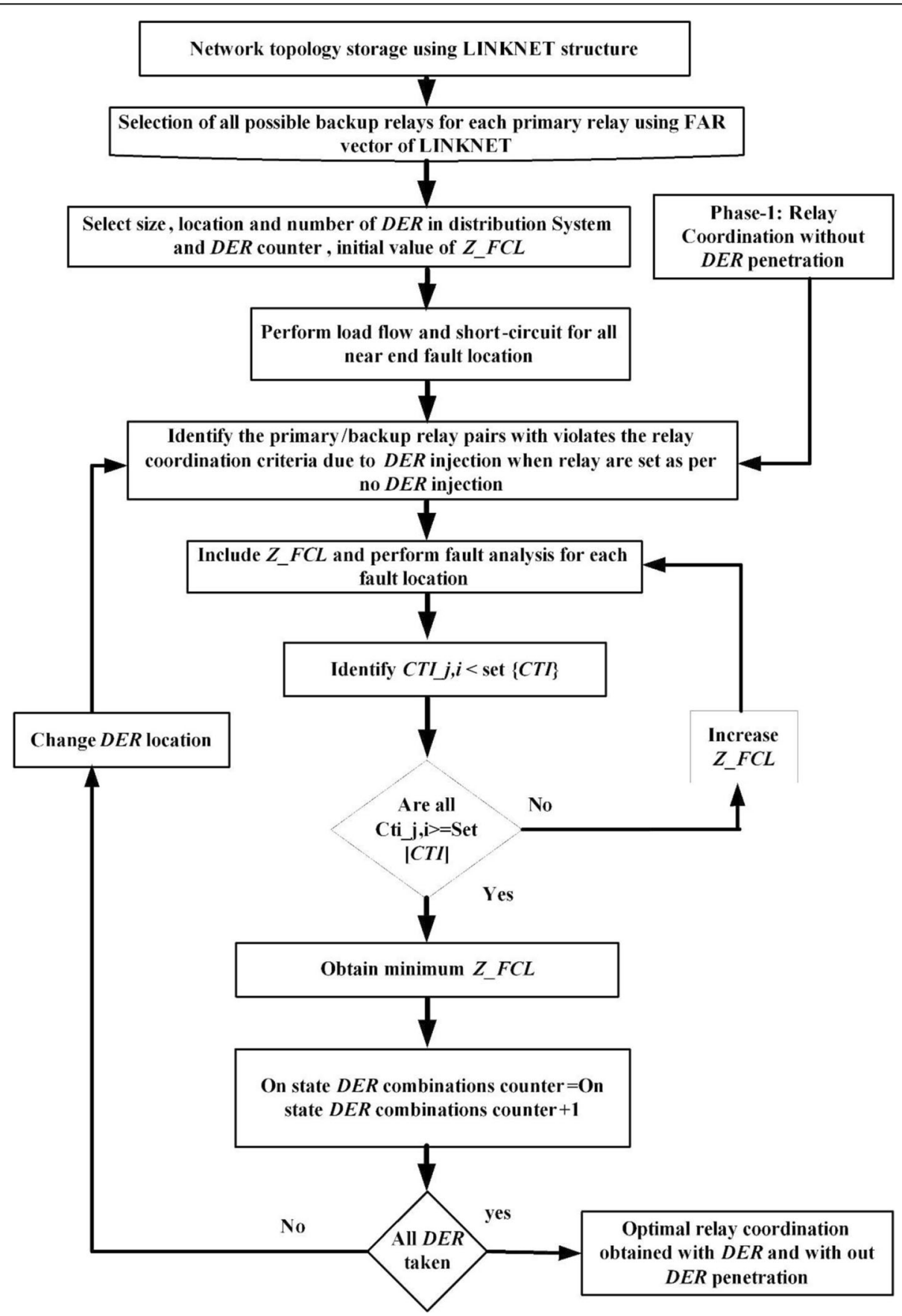

Fig. 4 Non-adaptive relaying scheme 
currents for adaptive relaying setting has been discussed. This technique is used to resolve relay mis-coordination problems under $D E R$ penetration in distribution system. Another technique has been discussed in [86], in which FCLs are connected in series with the DER and utility interconnection point to restore fault current levels to the original values (without $D E R$ ). The $F C L$ sizing problem is formulated as a non-linear programming problem, where the main objective is to minimize changes in fault current levels due to the addition of DER in the distribution systems. In $[87,88]$, multiple criteria such as the number of super conducting fault current limiter (SFCLs), fault current reduction and total operating time of the relays are considered for determining the optimal placement of SFCLs for protection coordination of relays in an electric power system with DERs [89]. Fast switching time feature of solid state fault current limiter (SSFCL) is also utilised for quick blocking of fault current from $D E R$ in the distribution systems. Moreover, SSFCLs are cost-efficient solution for minimizing the protection effect of $D E R$ on the distribution systems. In [90], GA is utilised to determine the optimum number, location and size of SSFCLs required in the network for blocking the DER fault impact. Sung-Hun et al. [91] developed an experimental model in which the application hybrid SFCL on protection coordination among the protective relays is investigated.

The effects of a resistive SFCL for determining the optimal size with protection coordination constraints for wind-turbine generator system (WTGS) is discussed in [92] for a practical distribution system. In [93], an approach for restoration of directional over-current relay coordination using different type $F C L$ is discussed in details. Another method is also discussed in [94, 95], for coordination of over current relays by considering the transient behaviour of $F C L$ on relay coordination for DER connected distribution networks.

In [5], a protection scheme based on the local information are utilised for developing an adaptive protection. In this protection scheme, trip characteristics of the relays are updated by detecting operating states of $D E R s$ (grid connected or islanded) and faulted section. The FCL size and settings of DOCRs settings are optimally determined by taking into account both grid-connected and islanded mode of operation of DERS. In [96], the application of evolutionary algorithms and linear programming solver are discussed for identifying the location of FCL and size in DER connected distribution systems without violating the protection constraints. Protection coordination strategy for DER connected meshed distribution systems is also analysed with the help of user-defined time inverse characteristics of directional inverse time overcurrent relays [97, 98]. In [99], another technique is proposed to maximize the penetration level of utility owned inverter based DER into distribution system under standard harmonic limits and protection coordination constraints. In this article additional constraints such as nodal voltage limits, total and individual harmonic distortion limits imposed by each $D E R$ units and relay coordination constraints are all together considered solving the projection coordination problem with the help of evolution algorithm.

In [100], another algorithm was published which discusses about the maximum penetration level of $D E R$ power in the distribution system under existing relay setting. In this algorithm, the DER locations are provided by the network operators, where the impacts of the $D E R s$ power is minimal for maximum penetration of $D E R$ power in their distribution systems. If the $D E R$ are customer based, then size of the $D E R$ are optimised by DER owner so that it will not impact the existing relay settings in the distribution systems. The algorithm for maximum DER penetration in the distribution system without resulting in loss of coordination among the installed relays is discussed in the Fig. 5.

In [101], dual relay characteristics are utilised for maintaining the relay coordination in DER connected distribution systems. These dual setting will provide the desired protection on forward and reverse fault current directions. As discussed above, implementation of this method requires the modern microprocessor based relays which can communicate among them self with the help of IEC61850 communication protocol. Additional Cost of communication infrastructure is main draw back in implementation of this approach.

\subsection{Multi-agent based protection schemes}

The use of agent based technology is gaining popularity for protection coordination application for power systems. In $[102,103]$, new protection coordination model, based on agent technology is discussed for protection coordination application for a DER connected distribution system. In [104], pair-to-pair agent based simulated communication for relay coordination has been developed. Another technique based on multi-agent which divides the network into different zones is discussed in [105]. This protection coordination scheme works on the principle of decentralized control for taking independent coordinated protection decision.

In [106], synchro phasor based communication techniques are also discussed for protection coordination application for $D E R$ based power systems. Islanding operation of low voltage distribution system having inverter connected (low short circuit capacity) renewable energy sources, imposes addition problems for optimal setting of over current relays $[107,108]$. The protection coordination for a strong distribution networks is normally designed for high fault current levels. But during micro 


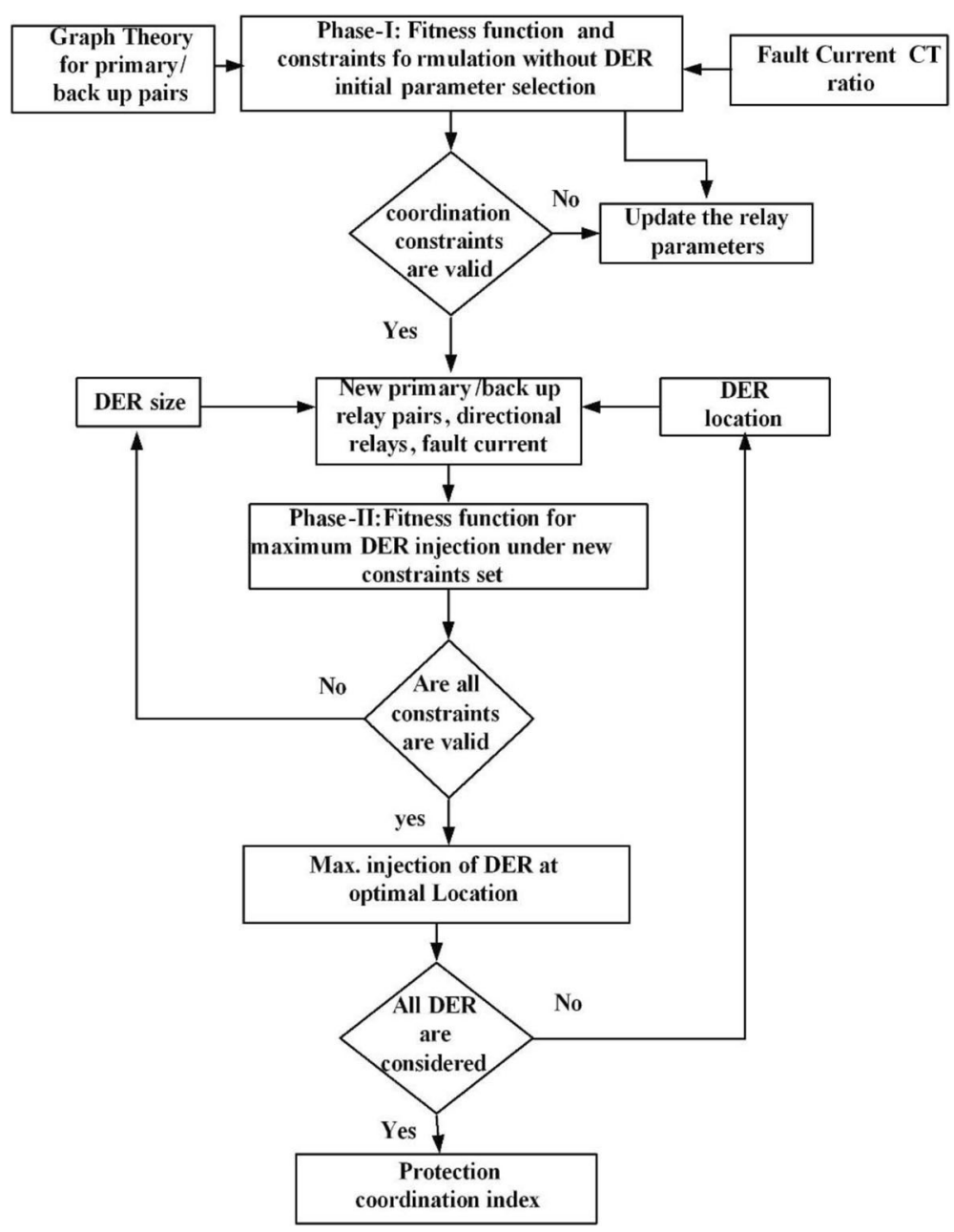

Fig. 5 maximum DER penetration

grid mode of operation, high fault-currents from the utility grid are absent. Since, most of the $D E R$ units will be connected to the low voltage distribution systems and these DER are photovoltaic in nature. The fault feeding capabilities of these inverter based photovoltaic systems are extremely and limited. Application of multi-agent based protection coordination is also extended for such system where speed of protection is very slow due to weak fault current. Figure 6 below shows the functional block of multi-agent based protection scheme used for relay coordination application discussed in [109].

Multi-agent based protection coordination is reliable solution for protection of isolated and grid confected active distribution systems. For such power systems decentralised control feature of multi-agent can be effectively utilised for protection application.

\subsection{Expert system based protection schemes}

An expert based system was used to provide rapid prototyping, friendly user interface, knowledge base construction, knowledge inference and external program capabilities features [110]. Expert system based protection scheme can solve the complexity of the protection coordination problem caused by the connection of $D E R$ in the distribution systems. It is quite helpful for utility engineers

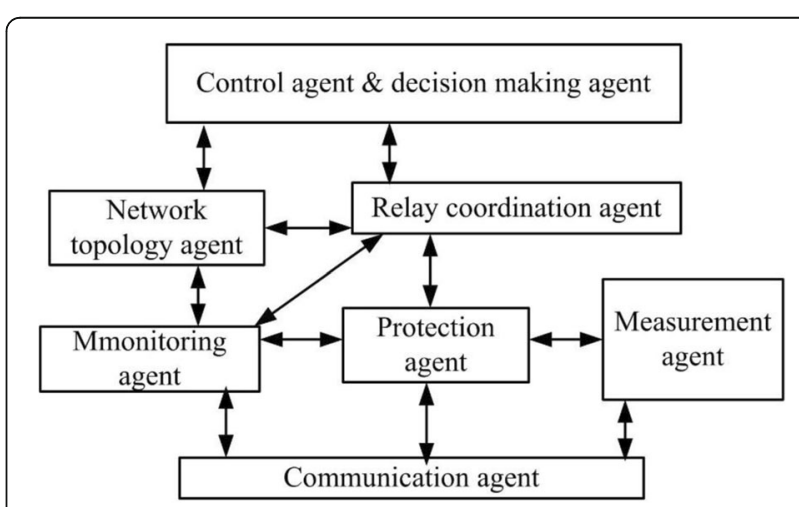

Fig. 6 Multi-agent based protection scheme 
to apply the expert system as a decision tool to investigate the impact of $D E R$ connection on relay coordination and to modify the settings of protective devices in the existing protection schemes [111]. Normal expert based systems solve the protection coordination problem by using available information in the knowledge base bank. An expert system provides an explanation of how and why it reached its decision. This can be utilised by the users to check the validity of the decision as well as the knowledge and inference procedures associated with it. This feature is crucial because it allows the users to update the knowledge base and repeatedly improve the inference. Figure 7 shows the important block of expert system based protection schemes.

Load flow and short circuit are input for formulation of rule base for implementation of relay coordination scheme in such protection techniques. Decision regarding the operation of particular relay is done in decision making unit of graphical user interface.

Accurate possible identification of network operating topologies is a challenge to create the data base for knowledge rule base.

\subsection{Dual setting protection schemes}

In some $D E R$ connected distribution systems, the backup relays may operate after long time delay and this may result inadequate protection in case when primary relays fails to trip. In [112], the bidirectional fault flow is utilised for tripping of near end reverse relays as backup relay. This protection coordination scheme is achieved by dual relay setting for each relay. One set of relay settings will work for forward fault current direction and other will work for the reverse direction of fault current. The implementation of protection scheme using dual relay setting is not yet reported.

\subsection{Voltage -current based protection schemes}

In radial distribution systems, the main source of the fault current is substation, which is feeded from the synchronous generators. The short circuit capacity of a synchronous generator is 6-8 times of the normal rating and protection relay can easily discriminate between the normal loading and fault condition due to this thick margin between loading and fault conditions. The decentralised microgrid mostly consists of solar based power generating sources for which there is a very thin margin between the normal loading and fault feeding capability. This thin margin creates problem for over current based relays to discriminate between fault and normal loading conditions. In microgrid modes it is observed that, there is small rise in load current from 110 to $150 \%$ during fault condition and simultaneously decrease in voltage below $80 \%$ of system voltage. In [112-114], a method is discussed which utilises the voltage and current signals for protection coordination application in DER connected distribution systems. The author has proposed a voltage-current time inverse protection scheme which can discriminate normal and fault condition in microgrid successfully. The operating time of voltage-current inverse relay characterises is given in (2) below.

$$
t_{v o c}=\frac{\delta^{*} T D S}{\left(\frac{I_{f}}{I_{p}} * \frac{V_{p}}{V_{n}}\right)^{\gamma}-1}
$$

Where, $t_{v o c}$ operating time of voltage current time inverse relay, $v_{p}$ is pickup voltage, $v_{n}$ nominal voltage and $\delta$ and $\gamma$ are user defined relay parameters in [108]. The operating zone of the voltage current time inverse relay is shown in Fig. 8. This protection scheme is also not yet implemented in the field as per the available literature.

The main above for distribution systems with $D E R$ penetration are summarised in Table 3.

\section{Review of methodologies used for formulation of fitness function in protection coordination}

There were different approaches adopted in the literature for formulation of fitness function for relay coordination

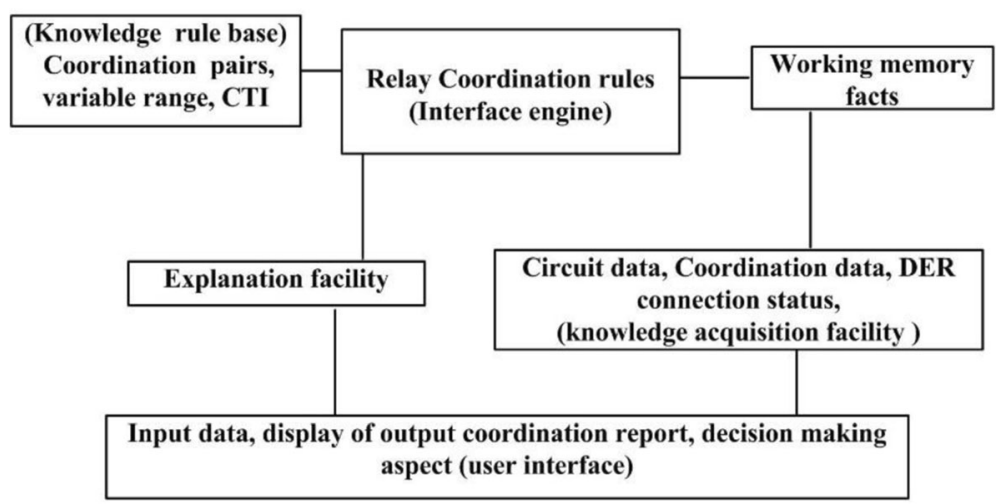

Fig. 7 Expert system based protection 


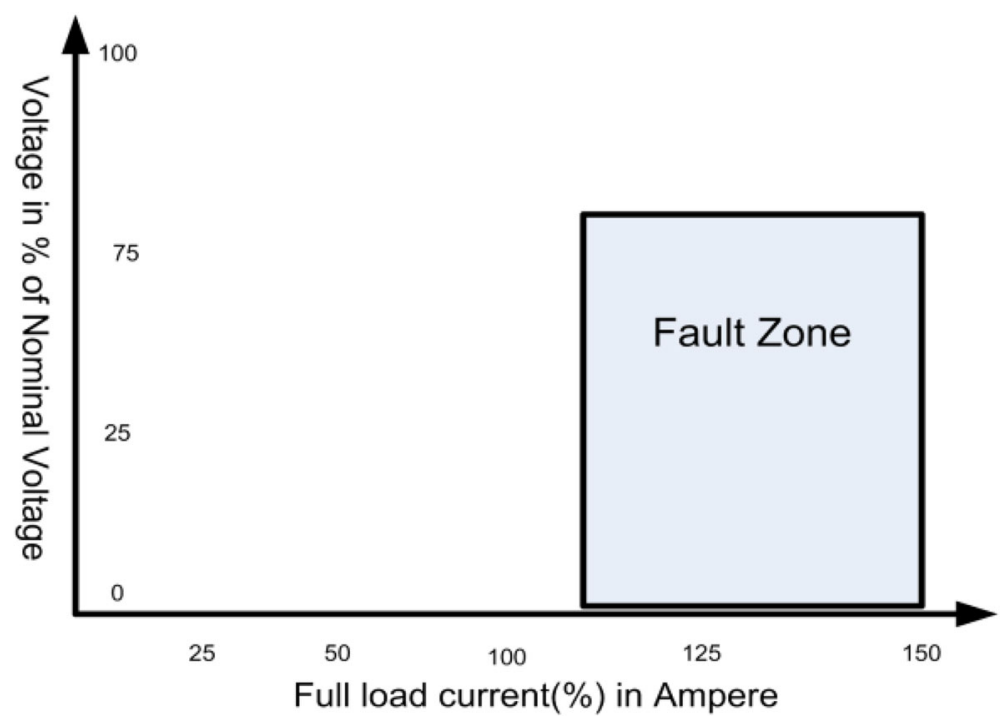

Fig. 8 Voltage-current time inverse relay operating zone

studies. The overall objective of all approaches is to maintain the desired coordination time margin between primary and corresponding backup relays and tripping of minimum relays. In [115], the fitness function is formulated as summation of operating time of all primary relays in the distribution systems and while in [37], it is formulated as minimization of total operating time of all primary relays for near end and far end faults. In [28], the fitness function is also defined minimization of operating time of primary relay as well as backup relays. However, few researcher proposed the fitness function as minimisation of time dial setting [33] of primary relays. In all above fitness function formulation techniques, it is observed that, relay coordination problem becomes highly nonlinear and non-convex optimization problem. The fast optimization algorithms can be effectively applied for for solving the relay coordination problems.

\section{Research gaps and future scope for protection coordination research work}

In his review article, the author have identified the various visible research gap and challenging for protection coordination schemes with and without DER connected distribution systems. These are as under.

i) Integration of $D E R$ changes the network topology and additional requirement of directional relays arises for which identification of correct backup relays becomes more complicated. However graph theory based approaches are used in the literature [46], but more reliable techniques will be required for highly complicated networks.

ii) Heavy interconnection of distribution networks results in an adequate change in the fault levels and some undesired relays may trip during the faults and these trippings are known as sympathetic trippings. Elimination of sympathetic tripping in the distribution systems during the network steady state and transient fault conditions with integration of $D E R$ s is an another unaddressed area [116].

iii) Integration of $D E R$ at distribution level may affect the protection requirement at upstream transmission for lines. For large scale penetration of $D E R$, the reach setting of distance relays installed at transmission line may get effected [8].

iv) From the literature, it is also observed that, the relay coordination problems are optimised without any upper limit of CTI [21, 43]. This results in delayed operation of backup over current relays particularly when the fault current contribution from Photovoltaic based DER is weak. Operating time of over current relays for such systems is enhanced by optimal selection of multiple time-inverse relay characterises during relay coordination studies [115].

v) It is observed that for small scale penetration of $D E R$, the protection coordination requirement are not much effected. A hybrid protection coordination algorithm is proposed in [116] in which minimum number of over current relays and smaller size of FCLs are utilised for maintaining the relay coordination in the distribution system during $D E R$ penetrations. However for large scale Megawatt integration from wind, effect is un-avoidable. An adaptive relaying algorithm with multiple relay group setting may be suitable protection coordination solution. In [117], author(s) have presented an idea for addressing the protection coordination issues with large scale penetration of $D E R$ in 
Table 3 Summary of protection schemes for distribution systems with DER Penetration

\begin{tabular}{|c|c|c|c|}
\hline Technique & Main feature & Merits & Demerits \\
\hline $\begin{array}{l}\text { Fault current limiter } \\
\text { based [68] }\end{array}$ & $\begin{array}{l}\text { Suitable for wind mill based DER } \\
\text { penetration }\end{array}$ & Block the fault current during faults & Costly \\
\hline $\begin{array}{l}\text { Harmonic restrained } \\
\text { Protection [93] }\end{array}$ & $\begin{array}{l}\text { The DER power is penetrated in } \\
\text { the power utility until the } \\
\text { allowed harmonic limit and } \\
\text { protection is maintained }\end{array}$ & $\begin{array}{l}\text { This approach is highly suitable for } \\
\text { inverter based } D E R \text {. }\end{array}$ & $\begin{array}{l}\text { Not applicable for non-invertor } \\
\text { based DER. }\end{array}$ \\
\hline Optimal sizing of DER. [90] & $\begin{array}{l}\text { DER power is penetrated at safe } \\
\text { location where existing } \\
\text { protection is least effected. }\end{array}$ & Existing protection may hold good. & Applicable for small penetration \\
\hline Adaptive Relaying [25] & $\begin{array}{l}\text { The relay setting are adopted } \\
\text { based on the changing network } \\
\text { topologies/configurations. }\end{array}$ & $\begin{array}{l}\text { This method is applicable for large } \\
\text { scale penetration from wind farms. }\end{array}$ & $\begin{array}{l}\text { Communication and numerical } \\
\text { relays are essential for design of } \\
\text { protection schemes. }\end{array}$ \\
\hline $\begin{array}{l}\text { Local adaptive } \\
\text { overcurrent based Protection } \\
\text { scheme [88]. }\end{array}$ & $\begin{array}{l}\text { It monitors local information } \\
\text { (current \& voltage) continuously } \\
\text { and re-calculate the relay setting } \\
\text { based on network topology. }\end{array}$ & $\begin{array}{l}\text { This technique is applicable for } \\
\text { both grid connected and islanded } \\
\text { mode systems. }\end{array}$ & $\begin{array}{l}\text { Fails during network dynamic } \\
\text { conditions, }\end{array}$ \\
\hline $\begin{array}{l}\text { A Novel adaptive } \\
\text { over-current Protection [96] }\end{array}$ & $\begin{array}{l}\text { DERs are considering as current } \\
\text { injection sources. Steady state } \\
\text { fault currents are calculated from } \\
\text { steady state equivalent reduction } \\
\text { of the system for design of } \\
\text { protection }\end{array}$ & $\begin{array}{l}\text { Capable to handle the network } \\
\text { dynamic changes. }\end{array}$ & $\begin{array}{l}\text { The algorithm run time increase } \\
\text { with system size. }\end{array}$ \\
\hline $\begin{array}{l}\text { Adaptive-relay-recloser-fuse } \\
\text { coordination. }\end{array}$ & $\begin{array}{l}\text { In this scheme, the relay/recloser } \\
\text { and fuse current are determined. } \\
\text { Based on the ratio relay and } \\
\text { fuse current }\end{array}$ & $\begin{array}{l}\text { This method is applicable for both } \\
\text { synchronous based DG and } \\
\text { Inverter based DG }\end{array}$ & $\begin{array}{l}\text { Sometimes it is not desirable } \\
\text { change the complete fast curve } \\
\text { of recloser [33]. }\end{array}$ \\
\hline $\begin{array}{l}\text { Online-Adaptive Over } \\
\text { current Protection }\end{array}$ & $\begin{array}{l}\text { Based on the network condition, } \\
\text { it will calculate the fault levels \& } \\
\text { relay setting will be updated by } \\
\text { using HIL IEC } 61850 \\
\text { communication. }\end{array}$ & $\begin{array}{l}\text { This protection scheme is } \\
\text { applicable for both grid } \\
\text { connected mode and Islanded } \\
\text { mode. }\end{array}$ & $\begin{array}{l}\text { Performance fails during network } \\
\text { changes. }\end{array}$ \\
\hline $\begin{array}{l}\text { Expert/Fuzzy based } \\
\text { protection scheme [104] }\end{array}$ & $\begin{array}{l}\text { Monitor the status of the DER } \\
\text { source, voltage phasor based } \\
\text { DFT technique and update the } \\
\text { pickup \& TDS settings based on } \\
\text { the network changes. }\end{array}$ & $\begin{array}{l}\text { This approach is suitable for } \\
\text { limited network topologies }\end{array}$ & $\begin{array}{l}\text { The identification of all potential } \\
\text { network topologies is difficult. }\end{array}$ \\
\hline $\begin{array}{l}\text { Group setting based } \\
\text { protection scheme [106] }\end{array}$ & $\begin{array}{l}\text { The multiple relay group setting } \\
\text { are identified based on the fault } \\
\text { level in network }\end{array}$ & $\begin{array}{l}\text { This approach is suitable for } \\
\text { multiple DER and series } \\
\text { compensated lines }\end{array}$ & $\begin{array}{l}\text { The identification of all potential } \\
\text { network topologies is difficult } \\
\text { and communication protocol are } \\
\text { essential. }\end{array}$ \\
\hline $\begin{array}{l}\text { Multi-agent based } \\
\text { protection [103] }\end{array}$ & $\begin{array}{l}\text { Coordinated decentralized } \\
\text { protection }\end{array}$ & Distributed protection control & $\begin{array}{l}\text { Requites the communicable } \\
\text { agents like relay, breaker etc. }\end{array}$ \\
\hline
\end{tabular}

power networks. The implementation of this scheme using the advance communication protocol in multi agent decentralised adaptive way is a new challenge for the protection engineers. Implementation of these relay coordination techniques in the distribution systems under $D E R$ penetration, is one of promising future area for relay in relay coordination studies.

vi) Weak fault current contribution for inverter based photovoltaic based generating system, makes the design of protection systems highly complicated. The design of sophisticated \& accurate protection is an emerging research area for the protection engineers.

\section{Conclusion}

In this review article, a detailed literature review for protection coordination for distribution systems with and without DER is discussed. This review article covers the review of all the notable protection coordination methods starting from the initial curve fitting, graph theory and application of exact optimization tools for solving the protection coordination problem for radial/ interconnected power systems. In these techniques, the relay coordination problem is formulated as linear and non-linear optimization problem and then solved using the different optimization techniques. These included, exact method and artificial intelligence based optimizations methods. 
Penetration of DER in distribution systems creates new protection coordination issues. Their impact on the network protection mainly depends upon their size and location and impact may be classified as large scale penetration or small scale penetration. Large scale penetration results in bidirectional flow of fault current over the most feeder. The existing unidirectional designed protection coordination schemes fail to clear the fault for such fault conditions. In the available literature, these problems are addressed by localising the DER impact and updating the protection setting wherever required. Therefore this review article makes a compressive review of all the protection schemes which are discussed in literature for maintaining the protection coordination under DER integration. Review is also extended protection issues arising in limited penetration of DER in power network and islanding mode of operation of power systems.

In this review article, visible research gaps and possible future scope of research in protection coordination has been also presented.

\section{Competing interests}

The authors declare that they have no competing interests.

Received: 28 October 2016 Accepted: 5 July 2017

Published online: 21 July 2017

\section{References}

1. Sudipta, G. S., Ghoshal, P., \& Ghosh, S. (2010). Optimal sizing and placement of distributed generation in a network system. International Journal of Electrical Power \& Energy Systems, 32(8), 849-856.

2. Central Electricity Authority (2016). Draft National Electricity. Ministry of Power Government of India, Delhi, l(6).

3. http://www.ieee.org/about/ieee_europe/june-july-august-sept_2015_ energy_news_bulletin.pdf.

4. Girgis, A., \& Brahma, S. (2004). Development of Adaptive protection scheme for distribution systems with high penetration of distributed generation. IEEE Transactions on Power Delivery, 19(1), 56-63.

5. Mahat, P., Chen, Z., Bak-Jensen, B., \& Bak, C. L. (2011). A Simple adaptive overcurrent protection of distribution systems with distributed generation. IEEE Transactions on Smart Grid, 2(3), 428-437.

6. Urdaneta, A. J., Ramon, N., \& Jimenez, L. G. P. (1988). Optimal coordination of directional relays in interconnected power system. IEEE Transactions on Power Delivery, 3(3), 903-911.

7. IEEE Std C37.90-1989 "IEEE Standard for Relays and Relay Systems Associated with Electric Power Apparatus," (ANSI), 1994.

8. Dubey, R., Samantaray, S. R., \& Panigrahi, B. K. (2014). Adaptive Distance Relaying Scheme for Transmission Network Connecting Wind Farms. Electric Power systems and components, 42(11), 457-464.

9. Olivares, D. E., et al. (2014). Trends in microgrid control. IEEE Transactions on Smart Grid, 5(4), 1905-1919.

10. Zocholl, S. E., Akamine, J. K., Hughes, A. E., Sachdev, M. S., \& Scharf, L. (1989). H. computer representations of overcurrent relay characteristics. IEEE Transactions on Power Delivery, 4(3), 1659-1667.

11. Whiting, J. P., \& Lidgate, D. (1983). Computer predictions of IDMT relay settings and performance for interconnected power systems. IEEE Generation, Transmission and Distribution, 130(3), 139-147.

12. Jenkins, L., Khincha, H. P., Shiva Kumar, S., \& Dash, P. (1992). An application of functional dependencies to the topological analysis of protection schemes. IEEE Transactions on Power Delivery, 7(1), 77-83.

13. Ramaswami, R., \& Mc-Guire, P. F. (1992). Integrated coordination and short circuit analysis for system protection. IEEE Transactions on Power Delivery, 7(3), 1112-1120.
14. Damborg, M. J., Ramaswami, R., Venkata, S. S., \& Postforoosh, J. M. (1984). Computer aided transmission protection system design, Part - I, algorithms. IEEE Transactions on Power Apparatus and Systems, 103(1), 51-59.

15. Knable, A. H. (1967). Electrical Power Systems Engineering: Problems and Solutions. New York: McGraw-Hill.

16. Shah, K. R., Detjen, E. D., \& Phadke, A. G. (1988). Feasibility of adaptive distribution protection system using computer overcurrent relaying concept. IEEE Transactions on Industry Applications, 24(5), 792-797.

17. Dwarkanath, M. H., \& Nowitz, I. (1980). An application of linear graph theory for coordination of directional overcurrent relays. Electric power problems-mathematical challenge, proceedings of the society for industrial and applied mathematics (SIAMS) conference Seattle, Washington; (pp. 104-114).

18. Damborg, M. J., Ramaswami, R., Jampala, A. K., \& Venkata, S. S. (1986). Application of relational database to computer aided engineering of transmission protection system. IEEE Transactions on Power Apparatus and Systems, 1(2), 187-193.

19. Damborg, M. J., Ramaswami, R., Venkata, S. S., \& Postforoosh, J. M. (1984). Computer aided transmission protective system design, Part - II, implementation and results. IEEE Transactions on Power Apparatus and Systems, 103(1), 60-65.

20. Rao, V. V. B., \& Rao, K. S. (1988). Computer aided coordination of directional relay: determination of break points. IEEE Transactions on Power Delivery, $3(2), 545-548$.

21. Prasad, V. C., Prakash Rao, K. S., \& Subba Rao, A. (1991). Coordination of directional relays without generating all circuits. IEEE Transactions on Power Delivery, 6(2), 584-590.

22. Jamali, S., \& Shateri, H. (2004). A branch-based method to break-point determination for coordination of over-current and distance relays. International Conference on Power System Technology POWERCON, 21-24, 1857-1862.

23. Gajbhiye, RK, De, A, Helwade, R, Soman, SA (2005). A simple and efficient approach to determination of minimum set of break point relays for transmission protection system coordination. In procc. of International conference on future power systems(pp. 1-5). Amsterdam.

24. Yue, Q. M., Lu, F., Yu, W. Y., \& Wang, J. (2006). A novel algorithm to determine minimum break point set for optimum cooperation of directional protection relays in multi-loop networks. IEEE Transactions on Power Delivery, 21(3), 1114-1119.

25. Alkaran, D. S., Vatani, M. R., Sanjari, M. J., Gharehpetian, G. B., \& Yatim, A. H. (2015). Overcurrent Relays Coordination in Interconnected Networks Using Accurate Analytical Method and Based on Determination of Fault Critical Point. IEEE Transactions on Power Delivery, 30(2), 870-977.

26. Urdaneta, A. J., Jimenez, L. G. P., Gomez, J. F., Feijoo, B., \& Gonzalez, M. (2000). Presolve analysis and interior point solutions of the linear programming coordination problem of directional overcurrent relay. Electrical Power and Energy System, 23, 819-825.

27. Mahari, A., \& Seyedi, H. (2013). An analytic approach for optimal coordination of overcurrent relays. IET Generation, Transmission and Distribution, 7(7), 674-680.

28. Pandi, VR, Zeineldin, HH, Xiao, W. Determining optimal location and size of distributed generation resources considering harmonic and protection coordination limits. IEEE Transactions on Power System, 28(2), 1245-1254.

29. Perez, L. G., \& Urdaneta, A. J. (1996). Optimal coordination of directional overcurrent relays considering definite time backup relaying. IEEE Transactions on Power Delivery, 14(4), 1276-1284.

30. Singh, M, Panigrahi, BK, Abhyankar, AR (2005). ptimal over currents relay coordination in distribution system. In Procc. of IEEE Conference on Energy, Automation and Signal (ICEAS)(pp. 1-5). Bhubaneswar.

31. Bedekar, P. P., Bhide, S. R., \& Kale, V. S. (2011). Determining optimum TDS and PS of overcurrent relays using linear programming technique. 8th International Conference on Electrical \& Engineering/Electronics and Information Technology (ECTI-CON)(pp. 700-703).

32. Abyaneh, H. A., Al-Daddagh, M., Kamangar, H., Sadeghi, S. H. H., \& Khan, R. A. J. (2003). A new optimal approach for coordination of overcurrent relays in interconnected power system. IEEE Transactions on Power Delivery, 15(2), 430-435.

33. Noghabi, A. S., Mashhadi, H. R., \& Sadeh, J. (2010). Optimal coordination of directional overcurrent relays considering different network topologies using interval linear programming. IEEE Transactions on Power Delivery, 25(3), 1348-1354. 
34. Laway, N. A., \& Gupta, H. O. (1994). An efficient method for generation, storage and retrieval of data for the coordination of directional relays. Electric Power Systems Research, 29(2), 147-152.

35. Irving, M. R., \& Elrafie, H. B. (1993). Linear programming for directional overcurrent relay coordination in interconnected power systems with constraint relaxation. Electric Power Systems Research, 27(3), 209-216.

36. Urdaneta, A. J., Perez, L. G., \& Restrepo, H. (Oct 1997). Optimal coordination of directional overcurrent relays considering dynamic changes in the network topology. IEEE Transactions on Power Delivery, 12(4), 1458-1464.

37. Birla, D., Mahaeshwari, R. P., \& Gupta, H. O. (2006). A new nonlinear directional overcurrent relay coordination technique and banes and boons of near end faults based approach. IEEE Transactions on Power Delivery, 21(3), 1176-1182.

38. Birla, D., Mahaeshwari, R. P., Gupta, H. O., Deep, K., \& Thakur, M. (2006). Applications of random search technique in directional overcurrent relay coordination. International Journal of Emerging Electric Power Systems, 7(1), $1-14$.

39. Keil, T., \& Jäger, J. (2008). Advanced coordination method for overcurrent protection relays using nonstandard tripping characteristics. IEEE Transactions on Power Delivery, 23(1), 52-57.

40. Razavi, F., Abyaneha, H. A., Al-Dabbaghb, M., Mohammadia, R., \& Torkaman, H. (2008). A new comprehensive genetic algorithm method for optimal overcurrent relays coordination. Electric Power Systems Research, 78, 713-720.

41. Karegar, H. K., Abyaneh, H. A., \& Al-Dabbagh, M. (2003). Flexible approaches for overcurrent relay characteristics simulation. Electric Power Systems Research, 66, 233-239.

42. Bedekar, P. P., \& Bhide, S. R. (2011). Optimum coordination of overcurrent relay timing using continuous genetic algorithm. Expert Systems with Applications, 38, 11286-11292.

43. Bedekar, P. P., \& Bhide, S. R. (2011). Optimum coordination of directional overcurrent relays using the hybrid GA-NLP approach. IEEE Transactions on Power Delivery, 26(1), 109-119.

44. So, C. W., \& Li, K. K. (2000). Overcurrent relay coordination by evolutionary programming. Electric Power Systems Research, 53, 83-90.

45. So, C. W., \& Li, K. K. (2000). Time coordination method for power system protection by evolutionary algorithm. IEEE Transactions on industrial Applications, 36(5), 1235-1240.

46. Saberi Noghabi, A., Sadeh, J., \& Rajabi Mashhadi, H. (2009). Considering different network topologies in optimal overcurrent relay coordination using a hybrid GA. IEEE Transactions on Power Delivery, 24(4), 1857-1863.

47. Mohammadi, R., Abyaneh, H. A., Rudsari, H. M., Fathi, S. H., \& Rastega, H. (2010). Overcurrent relays coordination considering the priority of constraints. IEEE Transactions on Power Delivery, 25(3), 1937-1948.

48. Zeineldin, H. H., El-Saadany, E. F., \& Salama, M. M. A. (2006). Optimal coordination of overcurrent relays using a modified particle swarm optimization. Electric Power Systems Research, 76, 988-995.

49. Mohamed, M. (2007). Mansour, Said F. Mekhamer, Nehad El-Sherif El-Kharbawe. A modified particle swarm optimizer for the coordination of directional overcurrent relays. IEEE Transactions on Power Delivery, 22(3), 1400-1410.

50. Deep, K, \& Bansal, JC (2009). Optimization of directional overcurrent relay times using Laplace Crossover Particle Swarm Optimization (LXPSO). 2009 World Congress on Nature \& Biologically Inspired Computing (NaBlC), (pp. 288-293). Coimbatore.

51. Liu, \& Yang, M.-T. (2012). A New Hybrid Nelder-Mead Particle Swarm Optimization for Coordination Optimization of Directional Overcurrent Relays. Mathematical Problems in Engineering, 2012, 1-18.

52. Thangaraj, R., Pant, M., \& Deep, K. (2010). Optimal coordination of overcurrent relays using modified differential evolution algorithms. Engineering Applications of Artificial Intelligence, 23, 820-829.

53. Thangaraj, R., Pant, M., \& Abraham, A. (2010). New mutation schemes for differential evolution algorithm and their application to the optimization of directional over-current relay settings. Applied Mathematics and Computation, 216, 532-544.

54. Moirangthem, J., Krishnanand, K. R., Dash, S. S., \& Ramaswami, R. (2013). Adaptive differential evolution algorithm for solving non-linear coordination problem of directional overcurrent relays. IET Generation, Transmission and Distribution, 4(7), 329-336.

55. Chelliah, T. R., Thangaraj, R., Allamsetty, S., \& Pant, M. (2014). Coordination of directional over current relay using opposition based chaotic differential evolution algorithm. International Journal of Electrical Power \& Energy Systems, 55, 341-350.
56. Ezzeddine, M., Kaczmarek, R., \& Iftikhar, M. U. (2011). Coordination of directional overcurrent relays using GA novel method to select their settings. IET Generation, Transmission and Distribution, 5(7), 743-750.

57. Payam, M. S. B., Ehsan Abdollahi, M., \& Dehkordi, A. S. (2011). Optimal coordination of directional overcurrent relay for power delivery system with a hybrid shuffled frog leaping algorith. Australian Journal of Basic and Applied Sciences, 5(12), 1949-1957.

58. Amraee, T. (2012). Coordination of directional overcurrent relays using seeker algorithm. IEEE Transactions on Power Delivery, 27(3), 1415-1422.

59. Barzegari, M., Bathaee, S. M. T., \& Alizadeh, M. (2010). Optimal coordination of directional overcurrent relays using harmony search algorithm. In Proceedings of 9th Conference on Environment and Electrical Engineering, EEEIC. (pp. 321-324)

60. Shih, M. Y., Castillo Salazar, C. A., \& Conde Enriquez, A. (2015). Adaptive directional over current coordination using ant colony optimization. IET Generation, Transmission and Distribution, 9(14), 1240-2049.

61. Albasri, F. A., Alroomi, A. R., \& Talaq, J. H. (2015). Optimal Coordination of Directional Over current Relays Using Biogeography based Optimization Algorithms. IEEE Transactions on Power Delivery, 30(4), 1810-1820.

62. Javadian, S. A. M., Haghifam, M.-R., Bathaee, S. M. T., \& Fotuhi Firoozabad, M. (2013). Adaptive centralized protection scheme for distribution systems with DG using risk analysis for protective devices placement. Electrical Power and Energy Systems, 44, 337-345.

63. Rezaei, N., \& Mr, H. (2008). Protection scheme for a distribution system with distributed generation using neural networks. International Journal of Electrical Power \& Energy Systems, 30(4), 235-241.

64. Sanaye-Pasand, M., \& Khorashadi-Zadeh, H. (2006). An Extended ANN-based high speed accurate distance protection algorithm. International Journal of Electrical Power \& Energy Systems, 28(6), 387-395.

65. Shih, M. Y., Enríquez, A. C., \& Trevi, L. M. T. (2014). On-line coordination of directional overcurrent relays: Performance evaluation among optimization algorithms. Electric Power Systems Research, 110, 122-132.

66. Rockefeller, G. D., Wagner, C. L., \& Linders, J. R. (1988). Adaptive transmission relaying concepts for improved performance. IEEE Transactions on Power Delivery, 3(4), 1446-1458

67. Jampala, A. K., Venkata, S. S., \& Domborg, M. J. (1989). Adaptive transmission protection: Concepts and computational issues. IEEE Transactions on Power Delivery, 4(1), 177-185.

68. Enriquez, A. C., Martinez, E. V., \& Altuve-Ferrer, H. J. (2013). A Time Overcurrent Adaptive Relay. International Journal of Electrical Power \& Energy Systems, 25(10), 841-847.

69. Chattopadhyay, B., Sachdev, M. S., \& Sidhu, T. S. (1996). An online relay coordination algorithm for adaptive protection using linear programming technique. IEEE Transactions on Power Delivery, 11(1), 165-173.

70. Mohammed, A., Haj-ahmed, \& Mahesh, S. (2014). Intelligent coordinated adaptive distance relaying. Electric Power Systems Research, 110, 163-171.

71. Calderaro, V., Galdi, V., Piccolo, A., \& Siano, P. (2007). Adaptive Relays for overhead line protection. Electric Power Systems Research, 77, 1552-1559.

72. Chabanloo, R. M., Abyaneh, H. A., Kamangar, S. S. H., \& Razavi, F. (2011). Optimal combined overcurrent and distance relays coordination incorporating intelligent overcurrent relay characteristics selection. IEEE Transactions on Power Delivery, 26(3), 1381-1391.

73. Sidhu, T. S., Baltazar, D. S., Palomino, R. M., \& Sachdev, M. S. (2004). A New approach for calculating zone-2 setting of distance relays and its use in an adaptive protection system. IEEE Transactions on Power Delivery, 19(1), 70-78.

74. Perez, L. G., \& J. (2001). Urdaneta. Optimal Computation of distance relays second zone timing in a mixed protection scheme with directional overcurrent relays. IEEE Transactions on Power Delivery, 16(3), 385-388.

75. Moravej, Z., Jazaeri, M., \& Gholamzadeh, M. (2012). Optimal coordination of distance and overcurrent relays in series compensated systems based on MAPSO. Energy Conversion and Management, 56, 140-151.

76. Basak, P., Chowdhury, S., Halderneedey, S., \& Chowdhury, S. P. (2012). A literature review on integration of distributed energy resources in the perspective of control, protection and stability of microgrid. Renewable and Sustainable Energy Reviews, 16, 5545-5556.

77. Central electricity authority ministry of power government of India. Annual report, 2013-14.

78. Mohamed, A. E., \& Zhao, Z. (2010). Grid-connected photovoltaic power systems: technical and potential problems-a review. Renewable and Sustainable Energy Reviews, 14, 112-129. 
79. Ma, J., Wang, X., Zhang, Y., Yang, Q., \& Phadke, A. G. (2012). A Novel adaptive current protection scheme for distribution systems with distributed generation. Electrical Power and Energy Systems, 43, 1460-1466.

80. Barker, P. P., \& De Mello, R. W. (2000). Determining the impact of distributed generation on power systems: part 1-radial distribution systems. IEEE Transactions on Power Delivery, 15(2), 486-493.

81. Leelaruji, R., \& Vanfretti, L. (2012). State-of-the-art in the industrial implementation of protective relay functions, communication mechanism and synchronized phasor capabilities for electric power systems protection. Renewable and Sustainable Energy Reviews, 16, 4385-4395.

82. Walid El-Khattam, T. S. (2008). Sidhu. Restoration Of directional overcurrent relay coordination in distributed generation systems utilizing fault current limiter. IEEE Transactions on Power Delivery, 23(2), 576-585.

83. El-Khattam, W., \& Sidhu, T. S. (2009). Resolving the impact of distribution renewable generation on directional over current relay coordination: a case study. IET Renewable Power Generation, 3(4), 415-425.

84. Ojaghi, M., Sudi, Z., \& Faiz, J. (2013). Implementation of full adaptive technique to optimal coordination of overcurrent relays. IEEE Transactions on Power Delivery, 28(1), 235-244.

85. Zeineldin, H. H., \& Xiao, W. (2011). Optimal fault current limiter sizing for distribution systems with DG, IEEE Power and Energy Society General Meeting(pp. 1-5). San Diego, CA.

86. Jo, H.-C., Joo, S.-K., \& Lee, K. (2013). Optimal placements of superconducting fault current limiters (SFCLs) for protection of electric power system with distributed generations (DGs). IEEE Transactions on superconductivity, 3(3), 5600-5604.

87. Kim, J.-S., Lim, S.-H., \& Kim, J.-C. (2011). Study on protective coordination for application of superconducting FCL. IEEE Transactions on superconductivity, 21(3), 2174-2177.

88. Kim, J.-S., Lim, S.-H., \& Kim, J.-C. (2012). Study on application method of superconducting fault current limiter for protective coordination of protective devices in a power distribution system. IEEE Transactions on Applied Superconductivity, 22(3), 1560-1564.

89. Ali, S., Shahriari, A., Varjani, A. Y., \& Haghifam, M. R. (2012). Cost reduction of distribution network protection in presence of distributed generation using optimized fault current limiter allocation. Electrical Power and Energy Systems, 43, 1453-1459.

90. Lim, S.-H., Kim, J.-S., Kim, M.-H., \& Kim, J.-C. (2012). Improvement of protection coordination of protective devices through application of a SFCL in a power distribution system with a dispersed generation. IEEE Transactions on Applied Superconductivity, 22(3), 5601001-5601004

91. Lee, H.-J., Son, G., \& Park, J.-W. (2011). Study On Wind-turbine generator system sizing considering voltage regulation and overcurrent relay coordination. IEEE Transactions on Power Systems, 26(3), 1283-1293.

92. Lee, H.-J., Son, G., \& Park, J.-W. (2011). A Study on wind-turbine generator system sizing considering overcurrent relay coordination with SFCL. IEEE Transactions on Applied Superconductivity, 3, 1240-1244.

93. Javadi, H., Ali Mousavi, S. M., \& Khederzadeh, M. (2013). A Novel approach to increase FCL application in preservation of over-current relays coordination in presence of asynchronous DGs. Electrical Power and Energy Systems, $44,810-815$.

94. Chabanloo, R. M., Abyaneh, H. A., Agheli, A., \& Rastegar, H. (2011). Overcurrent relays coordination considering transient behaviour of fault current limiter and distributed generation in distribution power network. IET Generation, Transmission and Distribution, 5(9), 903-911.

95. Najy, W., Zeineldin, H. H., \& Woon, W. (2013). Optimal protection coordination for microgrid with grid-connected and islanded capability. IEEE Transactions on Industrial Electronics, 60(4), 456-461.

96. Sharaf, H. M., Zeineldin, H. H., Ibrahim, D. K., \& Essam, E. L. (2015). A proposed coordination strategy for meshed distribution systems with DG considering user-defined characteristics of directional inverse time overcurrent relays. International Journal of Electrical Power \& Energy Systems, $65,49-58$

97. Zayandehroodi, H., Mohamed, A., Shareef, H., \& Farhoodnea, M. (2012). A novel neural network and backtracking based protection coordination scheme for distribution system with distributed generation. Electrical Power and Energy Systems, 43, 868-879.

98. Zeineldin, Mohamed, H. H., Khadkikar, Y. A., \& Pandi, V. (2013). A Protection Coordination Index for Evaluating Distributed Generation Impacts on Protection for Meshed Distribution Systems. IEEE Transactions on Smart Grid, 3(2), 1523-1532
99. Singh, M, Panigrahi, BK, Abhyankar, AR, Mukherjee, R, \& Kundu, R (2013). Optimal Location, Size and Protection Coordination of Distributed Generation in Distribution Network. In PROCEEDINGS of IEEE Symposium and computational intelligence, (pp. 16-19). Singapore.

100. Zeineldin, H. H., Sharaf, H. M., Ibrahim, D. K., \& El-Zahab, E. E.-D. A. (2015). Optimal Protection Coordination for Meshed Distribution Systems With DG Using Dual Setting Directional Over-Current Relays. IEEE Transactions on Smart Grid, 6(1), 115-123.

101. Wan, H., Member, K., Li, K., \& Wong, K. P. (2010). An Adaptive multiagent approach to protection relay coordination with distributed generators in industrial power distribution system. IEEE Transactions on Industrial Electronics, 46(5), 2118-2124.

102. Zhu, Y., Shaoqun, S., \& Wang, D. (2009). Multiagent-based wide area protection with best-effort adaptive strategy. Electrical Power and Energy Systems, 31, 94-99.

103. Laaksonen, H. J. (2010). Protection principles for future microgrids. IEEE Transactions on Power Electronics, 25(12), 2910-2919.

104. Chen, C.-R., Lee, C.-H., \& Chang, C.-J. (2013). Optimal Overcurrent relay coordination in power distribution system using a new approach. Electrical Power and Energy Systems, 45, 217-222.

105. Katiraei, F., Iravani, M. R., \& Lehn, P. W. (2005). Micro-grid autonomous operation during and subsequent to islanding process. IEEE Transactions on Power Delivery, 20(1), 284-292.

106. Sortomme, E., Venkata, S. S., \& Mitra, J. (2010). Microgrid protection using communication-assisted digital relays. IEEE Transactions on Power Delivery, 25(4), 2789-2797.

107. Velasco, D., Trujillo, C. L., Garcera, G., \& Figueres, E. (2010). Review of anti-islanding techniques in distributed generators. Renewable and Sustainable Energy Reviews, 14, 1608-1614.

108. Javadian, SAM, Haghifam, M-R, \& Rezaei, N (2009). A fault location and protection scheme for distribution systems in presence of DG using MLP neural networks. In: 2009 IEEE power engineering society general meeting, (pp. 1-8). Calgary, Alberta, Canada.

109. Wayne Hong, H., Chuen-Tsai, S., Mesa, V. M., \& Ng, S. (1991). Protective device coordination expert system. IEEE Transactions on Power Delivery, 26(1), 359-365.

110. Tuitemwong, K. Expert system for protection coordination of distribution system with distributed generators. International Journal of Electrical Power \& Energy Systems, 33(3), 466-471.

111. Zeineldin, H., Sharaf, H., Ibrahim, H. M., \& Abou El-Zahab, E. E. D. (2014). Optimal protection coordination for meshed distribution systems with DG using dual setting directional over-current relays. IEEE Transactions on Smart Grid, 6(1), 115-123.

112. Saleh, K. A., Zeineldin, H. H., Al-Hinai, A., \& El-Saadany, E. F. (2015). Optimal Coordination of Directional Overcurrent Relays Using a New Time-CurrentVoltage Characteristic. IEEE Transactions on Power Delivery, 30(2), 537-544.

113. Saleh, K. A., Zeineldin, H. H., Al-Hinai, \& El-Saanday, E. F. (2015). Dual-setting characteristic for directional overcurrent relays considering multiple fault locations. IET Generation, Transmission and Distribution, 99(12), 1332-1340.

114. Manohar, S., Panigrahi, B. K., \& Abhyankar, A. R. (2013). Optimal coordination of Directional Over-current Relays Using Teaching Learning-Based Optimization Algorithm. International Journal of Electrical Power \& Energy Systems, 5, 33-41.

115. Singh, M., \& Panigrahi, B. K. (2014). Minimization of operating time gap between primary relays at near and far ends in over current relay coordination. North American power symposium(pp. 7-9). USA: Washington State University.

116. Manohar Singh, B, Panigrahi, K, \& Abhyankar, AR (2013). A Hybrid protection scheme to mitigate the effect of distributed generation on relay coordination in distribution system. In PROCEEDINGS of IEEE PES General Meeting, (pp. 1-5). Vancouver, Canada.

117. Singh, M., Vishnuvarthan, T., \& Srivani, S. G. (2016). adaptive protection coordination schemes for power network under penetration of distributed energy resources. IET Generation, Transmission and Distribution, 10(15), 39193929. 